\title{
What is the Business Case for Improving Care for Patients with Complex Conditions?
}

\author{
Jeff Luck, MBA, PhD ${ }^{1,2}$, Patricia Parkerton, $M P H, P h D^{1,2}$, and Fred Hagigi, MBA, MPH, DrPH ${ }^{1,2}$ \\ ${ }^{1}$ VA HSR\&D Center for the Study of Healthcare Provider Behavior, Sepulveda, CA, USA; ${ }^{2}$ Department of Health Services, UCLA School of Public \\ Health, Los Angeles, CA, USA.
}

INTRODUCTION: Patients with complex conditions account for a disproportionate share of health care spending. Although evidence indicates that care for these patients could be provided more efficiently, the financial impact of mechanisms to improve the care they receive is unclear.

DESIGN/METHODS: Numerous mechanisms-emphasizing patient self-management, care coordination, and evidence-based guidelines-aim to improve the quality of care and outcomes for patients with complex conditions. Assessing the overall "business case" for these mechanisms requires carefully estimating all relevant costs and financial benefits, then comparing them in present value terms. Mechanisms that are not costsaving may still be implemented if they are costeffective. We reviewed articles in peer-reviewed journals, as well as reports available on publicly accessible websites, which contained data about the business case for mechanisms to improve care for patients with complex conditions.

MAIN RESULTS: Published studies do not provide clear evidence that current mechanisms are cost saving. This literature also has several major methodological shortcomings with respect to providing an understanding of the business case for these mechanisms.

CONCLUSIONS: Further research using standardized methodologies is needed to understand the business case for mechanisms to improve care for patients with complex conditions. Implications for VA business case analyses include the necessity of establishing appropriate time horizons, scope of services, and target populations, as well as considering the impact of existing VA systems.

KEY WORDS: business case; quality; outcomes; efficiency; cost effectiveness.

J Gen Intern Med 22(Suppl 3):396-402

DOI: $10.1007 / \mathrm{s} 11606-007-0293-2$

(c) Society of General Internal Medicine 2007

\section{INTRODUCTION}

Patients with complex chronic conditions account for a disproportionately high share of spending in any health care system. ${ }^{1}$ For example, the $23 \%$ of Medicare beneficiaries with 5 or more chronic conditions incur $68 \%$ of the program's spending. ${ }^{2}$ Among veterans age 65 and older, the 10 most expensive chronic conditions account for $66 \%$ of total VA costs for those persons. ${ }^{3}$

However, analyses at the national level also indicate that spending for patients with severe chronic illness could be greatly reduced without compromising the quality of care. ${ }^{4}$ For defined populations of patients, advocates of tools such as the Chronic Care Model or disease management assert that such mechanisms can both reduce costs and improve quality.

Policy makers and managers within health care systems want to know which specific interventions or tools can control costs for care of patients with complex conditions while maintaining or improving the quality of care and patient outcomes. Managers describe interventions or tools (henceforth "mechanisms") that meet these criteria as having a favorable "business case."

This paper reviews published findings about the business case for mechanisms to improve care for patients with complex conditions. It was originally prepared for the Department of Veterans Affairs (VA) 2006 State of the Art (SOTA) conference "Managing Complexity in Chronic Care." In the Methods section below, we (1) briefly describe the types of mechanisms used to improve care for patients with complex conditions; (2) outline a framework for analyzing the business case for these mechanisms; and (3) summarize the literature review process we undertook. Subsequent sections summarize the available evidence about the financial impact of implementing these mechanisms and conclude by highlighting priorities for future research and some implications for the VA health care system.

\section{METHODS}

\section{Mechanisms to Improve Care for Patients with Complex Conditions}

Patients with complex conditions have diverse and multiple diagnoses, including: diabetes and other chronic conditions; cancer; HIV disease; neurological disorders; autoimmune diseases; physical disabilities; and severe mental illness. These patients are often seen by multiple clinicians-specialists as well as primary care physicians-in multiple care settings. They have elevated risks of receiving poor quality care as well as incurring avoidable costs. ${ }^{1}$ These risks include: preventable hospitalizations; avoidable emergency department use; duplicate testing; polypharmacy; poor communication of essential clinical information across different physicians and care settings; potentially conflicting treatment strategies; and serious negative outcomes from poor compliance with treatment recommendations (see Fig. 1). 


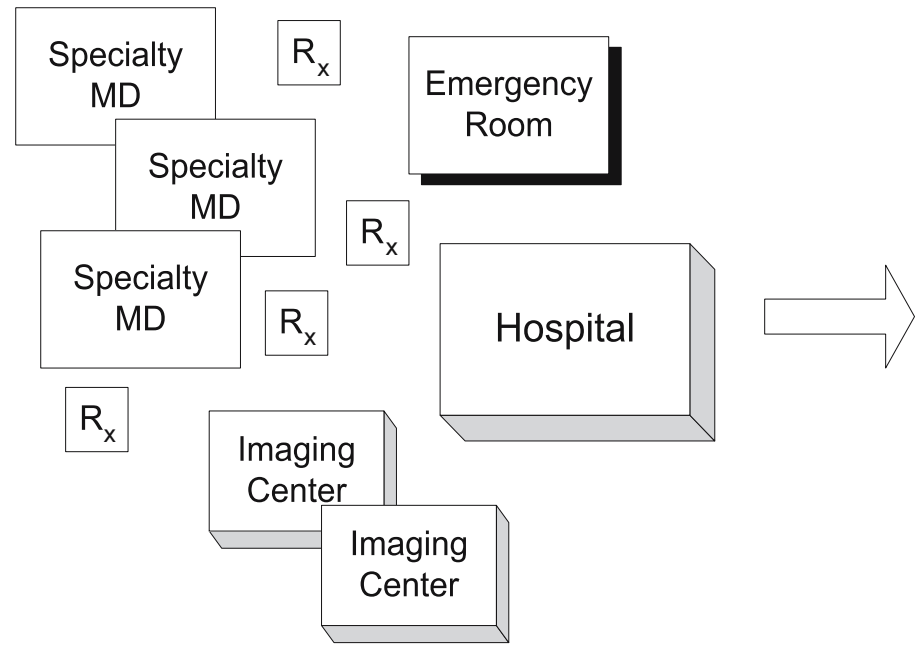

\section{Duplication \\ Poor Communication \\ Excess Utilization \\ Poor Outcomes \\ High Cost}

\section{Fragmented Care}

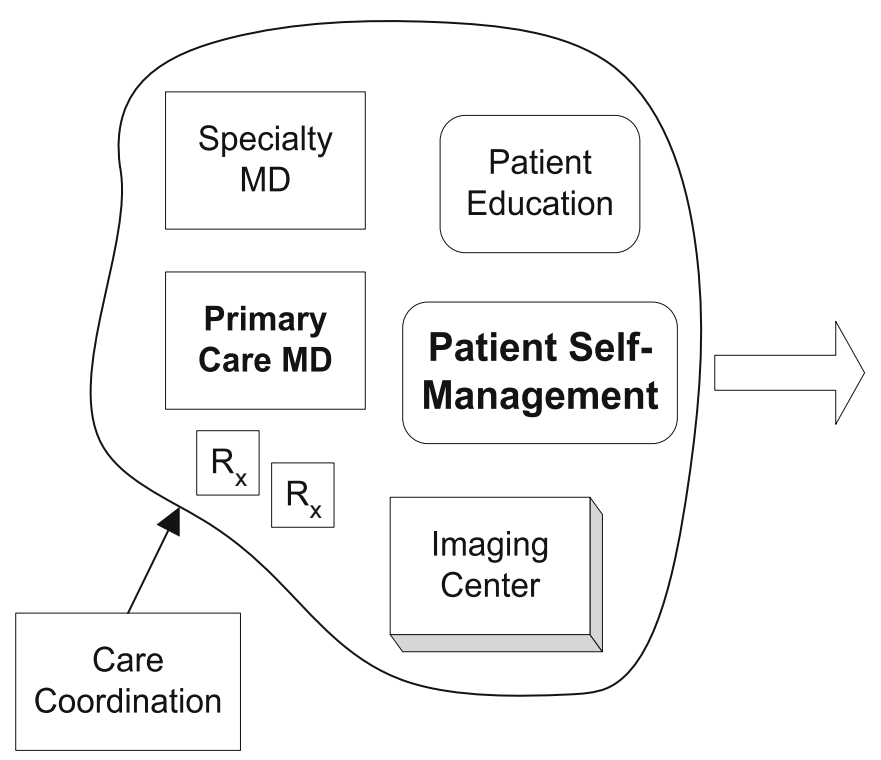

Clear Communication Appropriate Utilization

Higher Satisfaction Improved Process Better Outcomes Lower Cost?

Figure 1. Impact of Improved Care for Patients with Complex Conditions

A wide variety of mechanisms are employed to mitigate these risks and thereby improve care for patients with complex conditions (also see Fig. 1). Some of these mechanisms, such as the Chronic Care Model (CCM) and organized care management processes, are primarily implemented by physician organizations, whereas others, such as disease management, are most often implemented by health plans; ideally, complementary mechanisms should be coordinated among a patient's physicians and health plan. ${ }^{5-7}$ Table 1 describes these mechanisms in more detail.

Medicare is conducting several demonstration programs, each implementing different sets of mechanisms to improve care for fee-for-service beneficiaries with complex conditions. ${ }^{8}$ In the Physician Group Practice Demonstration, large multispecialty group practices will share in Medicare savings if they successfully improve cancer screening and care for 4 chronic conditions. Medicare Health Support is a large-scale disease management program for beneficiaries with $\mathrm{CHF}$ and/or complex diabetes. Contracts have been awarded to disease management vendors and health plans that have promised to achieve quality improvement and beneficiary satisfaction targets, as well as net financial savings of at least 5\%. Two other demonstrations are targeting high cost or severely chronically ill beneficiaries.

Many state Medicaid programs are implementing mechanisms to improve care for patients with chronic disease or other complex conditions. There is wide variation across states in the groups of patients targeted, the mechanisms chosen, and the implementation strategies used. ${ }^{9-11}$

\section{Business Case Analysis}

An analysis of the business case for implementing a set of mechanisms explicitly compares the estimated benefits of 


\section{Table 1. Mechanisms to Improve Care for Patients with Complex} Conditions

\begin{tabular}{l}
\hline \hline Mechanisms \\
\hline The Chronic Care Model (CCM) is a 6-element quality improvement \\
model for primary care of patients with chronic disease. ${ }^{54,55}$ \\
Physician organizations, whether or not they explicitly follow the CCM, \\
can employ one or more care management processes (CMPs). ${ }^{6,56-58}$ \\
These include: \\
• Self-management support \\
• Group visits ${ }^{59}$ \\
• Registries of patients with each chronic disease ${ }^{60,61}$ \\
•Evidence-based clinical practice guidelines \\
•Reminders (paper or electronic) \\
•Performance feedback to physicians \\
•Electronic medical records \\
•Case managers \\
Disease management programs, usually offered by health plans, \\
typically provide patients with information about their chronic disease(s), \\
promote positive health behaviors and treatment compliance, and \\
may provide data to the patients' physicians ${ }^{62-64}$ \\
Health plans and physician organizations employ case management to \\
coordinate the care provided to their sickest or most costly patients. ${ }^{65}$ \\
Telemedicine systems use information technology and \\
telecommunications to enable clinicians distant from patients to make \\
diagnoses, provide treatment recommendations, and conduct home \\
monitoring. ${ }^{66,67}$
\end{tabular}

those mechanisms with the costs of implementation. ${ }^{12}$ The business case is positive if financial benefits exceed costs while maintaining or improving quality. The business case would also be positive if implementing a set of mechanisms improved quality but did not produce a net cost increase.

Estimates of benefits and costs must meet specific criteria. ${ }^{13}$ First, all costs related to the implementation must be included. Second, future costs and benefits should be discounted to the present to account for the time value of money. If the present value of estimated benefits exceeds the present value of estimated costs, the financial return on investment (ROI) is positive.

Estimating Costs. For mechanisms to improve care of patients with complex conditions, estimated costs should include:

Startup costs, for example, new information systems, data collection and analyses to identify target patients, or initial training for physicians and staff;

Direct costs, for example, new staff, additional physician time, or additional nursing time to communicate with patients; Indirect costs $^{14}$ attributable to the mechanism, for example, higher utilization of screening tests or chronic disease medications, or senior management participation in implementation.

Estimating Benefits. Estimating financial and clinical benefits requires projecting how the mechanism(s) will change the frequency of future events. Estimating the impact of efficiency improvements, such as eliminating duplicate testing, is relatively straightforward. Estimating cost savings from reductions in more rare events such as preventable hospitalizations requires more sophisticated analyses. ${ }^{15}$ Estimating the benefits of preventing future complications of chronic disease is most challenging. The further in the future those complications would occur, the greater the uncertainty of the underlying statistical projections.
Two important methodological issues must be addressed in measuring benefits. ${ }^{16}$ First, cost reductions must be adjusted for expected regression to the mean. Patients are often identified to participate in a mechanism based on a history of high costs or a sentinel event, such as a hospitalization. However, some patients in the highest-cost group in a given year will inherently have lower costs in subsequent years. ${ }^{17}$

The second issue is selection bias. Patients who enroll in pilot or demonstration programs may be those most motivated to change their behavior, and therefore would have had reduced future costs even without the mechanism(s). Extrapolating benefits from these patients' experience may overestimate the benefit of the mechanism(s) for a larger population.

The business case for a mechanism is less favorable when the organization that bears its costs does not realize all the resulting benefits. For example, physician organizations that implement mechanisms to decrease avoidable hospitalizations may see the benefits accrue to health plans. A commercial health plan would not count some savings from preventing future complications of chronic disease, because they accrue after the patient is likely to have left the plan.

Cost-Effectiveness Analysis. The standard business case analysis method does not provide managers with adequate guidance about whether to implement mechanisms that improve quality but also increase costs, and therefore do not have a positive financial ROI. A health plan or integrated health care system may still decide to implement such mechanisms if they sufficiently improve health outcomes. Cost-effectiveness analysis (CEA) can help guide these decisions. ${ }^{18-20}$ CEA quantifies benefits in quality-adjusted life years (QALYs), not dollars. QALYs incorporate both years of life gained (delayed mortality) and future quality of life (reduced morbidity). CEA compares the cost per BALY gained from different mechanisms. Those with the lowest cost per BALY are recommended for implementation first, if incremental funds are available to the organization. However, if the overall budget for a population is fixed (as in the VA), implementing new, costeffective mechanisms means reducing funding for existing, less cost-effective activities, which can be quite difficult politically and organizationally. ${ }^{12,21}$

\section{Literature Review Process}

We performed a literature review to identify and synthesize published documents-articles in peer-reviewed journals as well as reports available on publicly accessible websites-that contained data about the business case for mechanisms to improve care for patients with complex conditions. To identify these documents, we initially conducted a series of keyword searches in PubMed, then subsequently searched (using PubMed or the Google search engine) for additional documents referenced in the articles and reports retrieved. Searches were constrained to documents published in English after 1995.

Search terms included the mechanisms described above and in Table 1, as well as terms focused on the business case (that is, costs, financial benefits, cost effectiveness, or economic evaluation) for those mechanisms. We further searched for articles on variation, utilization, and cost for patients in the VA health care system. We reviewed citations for over 700 articles or reports retrieved from these searches; over 200 abstracts or 
executive summaries were reviewed in detail. Because the volume of documents describing interventions for specific diseases was so large, we selected for deeper analysis: reviews that synthesized financial or economic findings from large numbers of studies; rigorous case study analyses; and reports on specific Medicare or Medicaid programs or VA studies. We synthesized the findings from these documents with respect to the aspects of business case analysis described above.

\section{RESULTS}

The published literature on the business case for mechanisms to improve care for patients with complex conditions is limited. The following meta-analyses, systematic reviews, or rigorous literature reviews summarize the benefits and costs of a variety of mechanisms:

Bodenheimer and colleagues ${ }^{22}$ review of 39 studies of the implementation of 1 or more CCM components for patients with CHF, asthma, or diabetes found mixed evidence of reduced cost or utilization. They noted that improvements in care for these diseases has the potential to reduce expenditures, if reimbursement systems are properly structured.

Richardson and colleagues ${ }^{23}$ reviewed 39 studies of the cost impact or cost effectiveness of interventions to support selfcare. Although most studies asserted positive economic results, the reviewers found most of the study designs to be seriously flawed.

The Congressional Budget Office ${ }^{24}$ examined 48 peer-reviewed studies of disease management programs for $\mathrm{CHF}, \mathrm{CAD}$, and diabetes. They did not find evidence that these programs reduced costs. Most studies, in fact, did not present cost data. (This review has been criticized for not including some peerreviewed studies, particularly those published in the journal Disease Management ${ }^{25}$ ).

Weingarten and colleagues ${ }^{26}$ performed a meta-analysis of 102 studies of the effectiveness of 118 disease management programs for 12 chronic diseases. Financial data were reported for only 6 of the programs. A subsequent systematic review of the same articles by Ofman and colleagues ${ }^{27}$ found that only 69 of 351 reported measures related to cost or utilization, and of these only 9 were statistically significant.

Goetzel and colleagues ${ }^{28}$ reviewed 44 published and highquality unpublished studies of the economic impact of disease management for 5 conditions. Programs for $\mathrm{CHF}$ or patients with multiple conditions appeared to have a positive ROI. ROI results were inconclusive for diabetes and asthma programs, whereas programs for depression were modestly cost increasing. Krause $^{29}$ performed a meta-analysis of the "direct economic outcomes" of 67 disease management programs for asthma, diabetes, and $\mathrm{CAD}$. One cost or utilization measure was included per study. A statistically significant effect size of 0.31 was found; patient disease severity was a statistically significant moderating variable.

Maciosek and colleagues ${ }^{30}$ reviewed the available literature on the cost effectiveness of 25 clinical preventive services recommended by the US Preventive Services Task Force or the Advisory Committee on Immunization Practices. Only 5 of the services were cost-saving; an additional 10 services had a cost/QALY below $\$ 35,000$.
Hailey and colleagues ${ }^{31}$ systematic review of 25 telemedicine studies that included economic analyses found indications that some telemedicine applications could reduce costs, but did not specify which of these applications apply to patients with complex conditions. Whitten and colleagues ${ }^{32}$ systematically reviewed 24 studies and did not find evidence that telemedicine was cost-effective, owing to methodological shortcomings of the studies' economic analyses.

Ouwens and colleagues ${ }^{33}$ performed a review of systematic reviews of "integrated care programmes" (comprising a variety of mechanisms) for patients with chronic disease. Seven of the 13 reviews addressed costs, of which 4 showed reductions (none statistically significant) and 3 showed unclear findings. Seven reviews addressed hospitalization, of which 6 showed reductions ( 3 of them statistically significant) and 1 showed unclear findings.

A few rigorous case studies provide some additional insights. Leatherman and colleagues ${ }^{34}$ reported on 4 carefully designed case studies of chronic disease management or wellness programs. All were estimated to produce a positive long-term financial impact. However, because initial costs were high while benefits accrued in the future, the business cases for the programs were not positive.

The Permanente Medical Group of Northern California (TPMG) instituted a disease management program for members with $\mathrm{CAD}, \mathrm{CHF}$, diabetes, or asthma. The program produced quality improvements but not cost savings. ${ }^{35}$ However, TPMG's preexisting organized processes of care may have limited the incremental cost savings realizable from the disease management program.

The Center for Studying Health System Change, reporting on its ongoing study of 12 health care markets nationwide, characterized disease management and case management as still being a financial "leap of faith" for employers and health plans. $^{36}$

The evidence regarding the benefits and costs of mechanisms to improve care for patients with complex conditions in Medicare and Medicaid is unclear. The Medicare demonstrations described above have not yet reported evaluation results. The Medicare Coordinated Care Demonstration, comprising 15 diverse programs (primarily offering disease management services), reported no clear quality benefits and no reduction in Part A and Part B services during its first 2 years. ${ }^{37}$ The diversity of states' Medicaid care coordination programs, as well as their relatively recent implementation, makes it difficult to comparatively evaluate their financial impact. For example, many Medicaid disease management programs report cost savings, but questions have also been raised about the validity of those estimates. ${ }^{38,39}$

The limited literature describing the benefits and costs of VA mechanisms to improve care for veterans with complex conditions provides both cautionary and hopeful findings. A rigorously evaluated primary care case management mechanism for severely ill veterans with diabetes, COPD, or CHF did not reduce rehospitalization as expected ${ }^{40} \mathrm{~A}$ multisite randomized trial of team-managed home-based primary care for severely ill veterans improved patient and caregiver quality of life, but also increased costs. ${ }^{41}$ A randomized multisite trial of a collaborative care model for bipolar disorder produced some improved outcomes over 3 years, and was cost neutral. ${ }^{68}$ 


\section{DISCUSSION}

Patients with complex conditions, especially those with multiple or severe chronic conditions, incur a large proportion of spending in any health care system. A variety of mechanismsemphasizing patient self-management, care coordination, and evidence-based guidelines-may help to control costs for those patients while improving or maintaining quality. Assessing the business case for these mechanisms requires carefully estimating all costs and financial benefits, then comparing them in present value terms. Mechanisms that are not cost-saving may still be implemented if they are cost-effective.

The published literature does not provide clear evidence that mechanisms to improve care for patients with complex conditions have a favorable business case, that is, are costsaving or can improve quality without increasing costs. One contributor to this lack of evidence is that, whereas most published studies of these mechanisms measure processes of care, outcomes, and/or patient satisfaction, only a minority measure costs and financial benefits.

This literature has several specific methodological shortcomings with respect to providing an understanding of the business case for mechanisms to improve care for patients with complex conditions:

1. Mechanisms evaluated. Most published studies report evaluations of individual programs, each comprising a unique set of component mechanisms. Because there is no standardized taxonomy of mechanisms, it is difficult to compare the impact of defined sets of mechanisms across studies or to assess the contributions of individual mechanisms. The problem is compounded when comparing published reviews, each of which has its own strategies for selecting which studies to include or exclude.

2. Cost estimates. As mentioned above, most published studies do not measure costs. Of those that do, only very few measure startup, direct, and indirect costs with adequate scope and precision to support business case analyses.

3. Benefit estimates. Benefit measures in published studies are usually nonfinancial (e.g., reduced hospitalizations or emergency department use), and are seldom adequately comprehensive in scope to capture all potential benefits.

4. Benefit timeframes. Studies commonly measure shortterm benefits ( 2 years or less), although other benefits take years to materialize. This is problematic because short-term utilization reductions may not translate into analogous lifetime cost savings.

5. ROI analysis. The shortcomings in most published studies' cost and benefit measurements make it virtually impossible to calculate or compare ROIs based on adequate present value analyses.

6. Cost-effectiveness analysis. Formal cost effectiveness analyses are seldom mentioned in published studies. And only 3 of the 11 reviews summarized above explicitly address the cost effectiveness of the studies they review.

\section{Future Research}

Further research is needed to understand the business case for mechanisms to improve case for patients with complex conditions. However, conducting such research is challenging: it involves evaluating multifaceted mechanisms at multiple sites; must account for variations in organizational structure and culture; should include randomized designs and control groups; must incorporate standardized, comprehensive measures of costs and financial and clinical outcomes; and may produce findings difficult to generalize across diverse underlying diseases. There is currently no standard set of cost or financial benefit measures or methodology for applying them. ${ }^{42}$ There is also no standard source for the QALY estimates needed for cost effectiveness analyses.

Standardized frameworks for evaluating the clinical and financial aspects of disease management programs may offer guidance for research about the business case for other mechanisms. These frameworks have been proposed from the perspective of health services research ${ }^{20}, 43,44$ and by disease management practitioners and industry associations. ${ }^{45-47}$ However, more data are needed about the effectiveness, costs, and benefits of programs to improve care for patients with multiple chronic conditions. ${ }^{1,48}$

\section{Implications for the VA Health Care System}

The VA is well positioned to measure the financial impact of mechanisms to improve care for patients with complex conditions and to reap the potential benefits from them. VA managers and researchers can draw several implications from the literature about these mechanisms in other settings.

First, VA business case analyses should use a sufficiently long time horizon in estimating costs and benefits. Although patients with complex conditions may not stay in a commercial health plan long enough for mechanisms to pay off, veterans retain VA eligibility for life. Because Medicare and Medicaid beneficiaries also have lifetime or long-term eligibility, the anticipated results from evaluations of mechanisms for patients with complex conditions in those programs may be especially informative for the VA.

Second, VA business case analyses must consider the cost of VA services that are not covered by commercial health plans or Medicare, particularly long-term care and mental health care. Estimated reductions in the utilization of these services may have a significant financial impact.

Third, the literature offers preliminary indications that targeting mechanisms to the highest-risk veterans, such as those with multiple chronic conditions, may produce greater financial benefits. ${ }^{1,49,50}$

Fourth, the VA should determine whether disease management or case management better meets the needs of veterans with complex conditions. Is the financial benefit greater from providing prevention and health promotion services to all veterans with chronic disease (many of whom are not complex) or from focusing intensively on the smaller number of highutilizing veterans (where disease has already progressed)? This question is especially important for the VA (and Medicare), because the prevalence of multiple chronic conditions is much higher than in the populations served by commercial disease management programs that usually focus on a single disease. ${ }^{51}$ Even in the commercial market, some health plans are emphasizing case management, believing it targets their resources more effectively. ${ }^{36,50}$ 
Fifth, the VA already has in place several of the mechanisms described above, such as the computerized patient record system (CPRS) to facilitate communication among multiple physicians, multidisciplinary care teams, the My HealtheVet online patient information system, performance feedback to facilities, practice guidelines, and the Quality Enhancement Research Initiative (QUERI). These capabilities may reduce the potential benefits of some other mechanisms. Conversely, they may help the VA to implement more focused or sophisticated mechanisms, such as telemedicine. ${ }^{52,53}$

Sixth, focused research could identify opportunities to improve care for veterans with complex conditions, and document the baseline against which mechanisms can be evaluated. Potential topics include characteristics of high-cost veterans, variations in utilization across VA facilities, and preventable VA hospitalizations.

\section{CONCLUSIONS}

Patients with complex conditions account for a large proportion of health care spending, and are often at risk for poor quality of care and outcomes. Although a variety of mechanisms aim to improve care for these patients, their long-term financial impact is still poorly understood. More research is needed to better understand their financial impact and cost effectiveness. The VA, because of its integrated financing and care provision, comprehensive information systems, and performance measurement capabilities, could play a leading role in evaluating the business case for such mechanisms and in implementing those that are shown to be cost-saving or costeffective.

Acknowledgments: This paper was originally prepared for the September 2006 VA State-of-the-Art (SOTA) conference, "Managing Complexity in Chronic Care." Drs. Luck and Hagigi were partially supported by VA HSR\&D Service Academic Experts in Implementation Research Grant \# IMA 04-161. Dr. Parkerton was partially supported by a VA HSR\&D QUERI Research Synthesis Grant.

Conflict of Interest: None disclosed.

Corresponding Author: Jeff Luck, MBA, PhD; Department of Health Services, UCLA School of Public Health, Box 951772, Los Angeles, CA 90095, USA (e-mail: jluck@ucla.edu).

\section{REFERENCES}

1. Vogeli C, Shields A, Lee T, et al. Multiple chronic conditions: prevalence and implications for patient management, outcomes, and costs. Background paper for VA 2006 SOTA Conference "Managing Complexity in Chronic Care", 2006.

2. Anderson GF. Medicare and chronic conditions. N Engl J Med. 2005;353 (3):305-9.

3. Yu W, Ravelo A, Wagner TH, Barnett PG. The relationships among age, chronic conditions, and healthcare costs. Am J Manag Care. 2004;10 (12):909-16.

4. Dartmouth Atlas Project. The Care of Patients with Severe Chronic Illness: A Report on the Medicare Program by the Dartmouth Atlas Project. 2006, Center for the Evaluative Clinical Sciences: Hannover, NH.

5. Berenson RA. Challenging the Status Quo in Chronic Disease Care: Seven Case Studies. Oakland, CA: California Healthcare Foundation; 2006.

6. Casalino LP. Disease management and the organization of physician practice. JAMA. 2005;293(4):485-8.
7. Medicare Payment Advisory Commission, Report to the Congress: Increasing the Value of Medicare. 2006. p. 31-44.

8. Guterman S, Serber M. Enahancing Value in Medicare: Demonstrations and Other Initiatives to Improve the Program. Washington, DC: Commonwealth Fund; 2007.

9. Gillespie J, Mollica R. Coordinating care for the chronically ill: How do we get there from here? Portland, ME: National Academy for State Health Policy; 2003.

10. NGA Center for Best Practices, Disease Management: The New Tool for Cost Containment and Quality Care. 2003, National Governors Association.

11. Silow-Carroll S, Alteras T. Stretching state health care dollars: Care management to enhance cost-effectiveness. The Commonwealth Fund, 2004

12. Yano E, Luck J, Hagigi F, Liu C. Building the Business Case for Quality Improvement and Health Services Research. In: Department of Veterans Affairs Health Services Research \& Development Service Meeting. Baltimore, MD; 2005.

13. Gapenski LC. Healthcare finance: An introduction to accounting and financial management. 2nd ed. Chicago, IL: Health Administration Press, 2002.

14. Finkler S, Ward D. Essentials of Cost Accounting for Health Care Organizations. 2nd ed. NY, NY: Aspen Publishers, 1999.

15. Linden AL. What will it take for disease management to demonstrate a return on investment? New perspectives on an old theme. Am J Manag Care. 2006;12(4):217-22

16. Fetterolf D, Wennberg D, Devries A. Estimating the return on investment in disease management programs using a pre-post analysis. Dis Manag. 2004;7(1):5-23.

17. Congressional Budget Office. High-Cost Medicare Beneficiaries. Washington, DC: Congress of the United States; 2005.

18. Gold MR, Siegel JE, Russell LB, Weinstein MC, eds. Cost-Effectiveness in Health and Medicine. New York: Oxford University Press; 1996.

19. Neumann PJ, Rosen AB, Weinstein MC. Medicare and cost-effectiveness analysis. N Engl J Med. 2005;353(14): 1516-22.

20. Selby JV, Scanlon D, Lafata JE, Villagra V, Beich J, Salber PR. Determining the value of disease management programs. Jt Comm J Qual Saf. 2003;29(9):491-9.

21. Oberlander $\mathbf{J}$. Health reform interrupted: the unraveling of the Oregon Health Plan. Health Aff (Millwood). 2007;26(1):w96-w105.

22. Bodenheimer $\mathbf{T}$, Wagner $\mathbf{E H}$, Grumbach $\mathbf{K}$. Improving primary care for patients with chronic illness: the chronic care model, Part 2. JAMA. 2002;288(15):1909-14.

23. Richardson G, Gravelle H, Weatherly H, Ritchie G. Cost-effectiveness of interventions to support self-care: a systematic review. Int J Technol Assess Health Care. 2005;21(4):423-32.

24. Congressional Budget Office. An analysis of the literature on disease managmeent programs. Washington, DC: Congress of the United States; 2004.

25. Nash DB. An open letter to the disease management community. Dis Manag. 2004;7(4):265-6.

26. Weingarten SR, Henning JM, Badamgarav E, et al. Interventions used in disease management programmes for patients with chronic illnesswhich ones work? Meta-analysis of published reports. BMJ. 2002;325 (7370):925

27. Ofman JJ, Badamgarav E, Henning JM, et al. Does disease management improve clinical and economic outcomes in patients with chronic diseases? A systematic review. Am J Med. 2004;117(3):182-92.

28. Goetzel RZ, Ozminowski RJ, Villagra VG, Duffy J. Return on Investment in Disease Management: A Review. Health Care Financ Rev. 2005;26(4): 1-19.

29. Krause DS. Economic effectiveness of disease management programs: a meta-analysis. Dis Manag. 2005;8(2):114-34.

30. Maciosek MV, Coffield AB, Edwards NM, Flottemesch TJ, Goodman MJ, Solberg LI. Priorities among effective clinical preventive services: results of a systematic review and analysis. Am J Prev Med. 2006;31 (1):52-61.

31. Hailey D, Ohinmaa A, Roine R. Study quality and evidence of benefit in recent assessments of telemedicine. J Telemed Telecare. 2004;10 (6):318-24.

32. Whitten PS, Mair FS, Haycox A, May CR, Williams TL, Hellmich S. Systematic review of cost effectiveness studies of telemedicine interventions. BMJ. 2002;324(7351):1434-7.

33. Ouwens M, Wollersheim H, Hermens $\mathbf{R}$, Hulscher $\mathbf{M}$, Grol $\mathbf{R}$. Integrated care programmes for chronically ill patients: a review of systematic reviews. Int J Qual Health Care. 2005;17(2):141-6. 
34. Leatherman S, Berwick D, Iles $\mathbf{D}$, et al. The business case for quality: case studies and an analysis. Health Aff (Millwood). 2003;22 (2):17-30.

35. Fireman B, Bartlett J, Selby J. Can disease management reduce health care costs by improving quality? Health Aff (Millwood). 2004;23(6):63-75.

36. Short A, Mays G, Mittler J. Disease management: a leap of faith to lower-cost, higher-quality health care. Issue Brief Cent Stud Health Syst Change. 2003;(69): 1-4.

37. Brown R, Peikes D, Chen A, Ng J, Schore J, Soh C. The Evaluation of the Medicare Coordinated Care Demonstration: Findings for the First Two Years. Princeton, NJ: Mathematica Policy Research; 2007.

38. Health Strategies Consultancy, Disease Management in Medicaid, 2004. 2006, California Healthcare Foundation.

39. Wheatley B. Disease management: findings from leading state programs. State Coverage Initiat Issue Brief. 2002;3(3):1-6.

40. Weinberger M, Oddone EZ, Henderson WG. Does increased access to primary care reduce hospital readmissions? Veterans Affairs Cooperative Study Group on Primary Care and Hospital Readmission. N Engl J Med. 1996;334(22): 1441-7.

41. Hughes SL, Weaver FM, Giobbie-Hurder A, et al. Effectiveness of teammanaged home-based primary care: a randomized multicenter trial. JAMA. 2000;284(22):2877-85.

42. Matheson D, Wilkins A, Psacharopoulos D. Realizing the Promise of Disease Management: Payer Trends and Opportunities in the United States. 2006, Boston Consulting Group.

43. Linden A, Roberts N. A user's guide to the disease management literature: recommendations for reporting and assessing program outcomes. Am J Manag Care. 2005; 11(2):113-20.

44. Villagra V. Strategies to control costs and quality: a focus on outcomes research for disease management. Med Care. 2004;42(4 Suppl):III24-30.

45. Disease Management Purchasing Consortium. Incorrect Cost Measurement Found to Overstate Savings from Disease State Management Programs: Industry Experts Concur on and Urge Adoption of Revised Industry Standard. 2005 [cited 1 August 2006]; Available from: http:// www.dismgmt.com/roi_release.asp.

46. Fitzner K, Sidorov J, Fetterolf $\mathbf{D}$, et al. Principles for assessing disease management outcomes. Dis Manag. 2004;7(3):191-201.

47. Wilson TW, Gruen J, William T, et al. Assessing return on investment of defined-population disease management interventions. Jt Comm J Qual Saf. 2004;30(11):614-21.

48. Werner RW, Greenfield S, Fung C, Turner BJ. Measuring Quality of Care in Complex Patients: Findings from a Conference Organized by the Society of General Internal Medicine. Washington, DC: Society of General Internal Medicine; 2006.

49. Katon W, Unutzer J, Fan MY, et al. Cost-effectiveness and net benefit of enhanced treatment of depression for older adults with diabetes and depression. Diabetes Care. 2006;29(2):265-70.

50. Mays GP, Claxton G, White J. Managed care rebound? Recent changes in health plans' cost containment strategies. Health Aff (Millwood), 2004. Suppl Web Exclusives: p. W4-427-36.
51. Horvath J, Berenson R. Developing the Right Approaches to Chronic Care in Medicare. Center for American Progress. 2004

52. Joseph AM. Care coordination and telehealth technology in promoting self-management among chronically ill patients. Telemed J E Health. 2006; 12(2):156-9

53. Whited JD, Datta SK, Aiello LM, et al. A modeled economic analysis of a digital tele-ophthalmology system as used by three federal health care agencies for detecting proliferative diabetic retinopathy. Telemed $\mathrm{J}$ E Health. 2005; 11(6):641-51.

54. Wagner EH, Austin BT, Davis C, Hindmarsh M, Schaefer J, Bonomi A. Improving chronic illness care: translating evidence into action. Health Aff. (Millwood) 2001;20(6):64-78.

55. Bodenheimer T, Wagner EH, Grumbach $\mathbf{K}$. Improving primary care for patients with chronic illness. JAMA. 2002;288(14):1775-9.

56. Casalino L, Gillies RR, Shortell SM, et al. External incentives, information technology, and organized processes to improve health car quality for patients with chronic diseases. JAMA. 2003;289(4):434-41.

57. Rittenhouse DR, Robinson JC. Improving quality in Medicaid: the use of care management processes for chronic illness and preventive care Med Care. 2006;44(1):47-54.

58. Rundall TG, Shortell SM, Wang MC, et al. As good as it gets? Chronic care management in nine leading US physician organisations. BMJ. 2002;325(7370):958-61

59. California Healthcare Foundation. Conference Highlights-Chronic Disease Care: Better Ideas for Solving Real World Problems. 2006.

60. Metzger J. Using computerized registries in chronic disease care. Oakland, CA: California Healthcare Foundation; 2004.

61. Schmittdiel J, Bodenheimer T, Solomon NA, Gillies RR, Shortell SM. Brief report: the prevalence and use of chronic disease registries in physician organizations. A national survey. J Gen Intern Med. 2005;20 (9):855-8

62. Disease Management Association of America. DMAA Definition of Disease Management. [cited 31 July 2006]; Available from: http:// www.dmaa.org/definition.html.

63. Sprague L. Disease management to population-based health: steps in the right direction? NHPF Issue Brief. 2003(791):1-16.

64. Welch WP, Bergsten C, Cutler C, Bocchino C, Smith RI. Disease management practices of health plans. Am J Manag Care. 2002;8 (4):353-61.

65. Gold M, Lake T, Black WE, Smith M. Challenges in improving care for high-risk seniors in Medicare. Health Aff (Millwood). Suppl Web Exclusives. 2005; W5-199-W5-211.

66. Bashshur RL. Telemedicine/telehealth: an international perspective Telemedicine and health care. Telemed J E Health. 2002;8(1):5-12.

67. Krupinski E, Nypaver M, Poropatich R, Ellis D, Safwat R, Sapci H. Telemedicine/telehealth: an international perspective. Clinical applications in telemedicine/telehealth. Telemed J E Health. 2002;8(1):13-34.

68. Bauer MS, McBride L, Willford WO, et al. Collaborative care for bipolar disorder: Part II. Impact on outcome, function, and costs. Psychiatric Services. 2006;57:937-945. 